\title{
NUMERICAL SIMULATION OF NITROGEN OXIDE FORMATION IN DUST FURNACES
}

\author{
Bulbul Ongar \\ Department of Power Engineering ${ }^{l}$ \\ Department of Thermal Physics and Technical Physics \\ Al-Farabi Kazakh National University \\ 71 Al-Farabi ave., Almaty, Republic of Kazakhstan, 050040 \\ Hristo Beloev \\ Department of Thermotechnics, Hydraulics and Environmental Engineering ${ }^{2}$ \\ Iliya Iliev $\bowtie$ \\ Department of Thermotechnics, Hydraulics and Environmental Engineering ${ }^{2}$ \\ iki@uni-ruse.bg \\ Assem Ibrasheva \\ Department of Automation and Control \\ Satbayev University \\ 22 a Satbayev str., Almaty, Republic of Kazakhstan, 050013 \\ Anara Yegzekova \\ Department of Power Engineering ${ }^{l}$ \\ ${ }^{1}$ Academy of Logistics and Transport \\ 97 Shevchenko str., Almaty, Republic of Kazakhstan, 050012 \\ ${ }^{2}$ University of Ruse \\ 8 Studentska str., Ruse, Bulgaria, 7017
}

$\triangle$ Corresponding author

\begin{abstract}
Even though natural sources of air pollution account for over $50 \%$ of sulphur compounds, $93 \%$ of nitrogen oxide which are the most dangerous artificial anthropogenic sources of air pollution and primarily associated with the combustion of fossil fuel. Coal-fired thermal power plants and industrial fuel-burning plants that emit large quantities of nitrogen oxides $\left(\mathrm{NO}\right.$ and $\left.\mathrm{NO}_{2}\right)$, solids (ash, dust, soot), as well as carbon oxides, aldehydes, organic acids into the atmosphere pollute the environment in majority. In the present work, a mathematical model and a scheme for calculating the formation of nitrogen oxide has been developed. Also, the dependence of the rate of release of fuel nitrogen from coal particles at the initial stage of gasification and content of volatiles has been obtained. The main regularities of the formation of $\mathrm{NO}_{x}$ at the initial section of the flame in the ignition zone of the swirl burner flame during the combustion of Ekibastuz coal have been revealed. Modern environmental requirements for the modernization of existing and the creation of new heat and power facilities determine the exceptional relevance of the development of effective methods and constructions to reduce emissions of nitrogen oxides, sulfur oxides and ash to 200,300 , and $100 \mathrm{mg} / \mathrm{nm}^{3}$ at $\alpha=1.4$. The dust consumption in all experiments was kept constant and amounted to $0.042 \mathrm{~g} / \mathrm{s}$, as well as with the results of calculating the thermal decomposition of the Ekibastuz coal dust, the recombination of atomic nitrogen into nitrogen molecules, and the kinetics of the formation of fuel nitric oxide.

It was found that despite the presence of oxygen in Ekibastuz coal for gases $O^{d a f}=11.8 \%$ in an inert atmosphere, nitrogen oxides are not formed.
\end{abstract}

Keywords: Coal particles, Burner, Nitrogen oxides, Atomic nitrogen, Molecular nitrogen.

DOI: $10.21303 / 2461-4262.2022 .002102$

\section{Introduction}

At present, the issues of environmental protection are brought to the fore among the universal values. The successful solution of these issues depends not only on the human health of the 
present and future generations but also on the development of civilization of humanity itself. Even now, the rate and scale of anthropogenic impact exceed the adaptive capacity of the biosphere, and therefore irreversible processes occur in nature, leading to environmental disasters. The relevance of solving the problems described in the aim is determined by the fact that one of the main sources of harmful effects on the environment is energy enterprises, and among them, the dominant role is occupied by thermal power plants [1]. The most common environmentally hazardous emissions from thermal power plants are nitrogen oxides $\left(\mathrm{NO}_{x}\right)$ through exhaust. A decisive role in reducing nitrogen oxide emissions is played by regime-technological methods aimed at suppressing the formation of $\mathrm{NO}_{x}$ in the boiler furnaces and including step-by-step combustion, non-stoichiometric combustion, flue gas recirculation, moisture injection, etc. However, it is necessary to further improve these methods, which make it possible to meet the regulatory requirements for $\mathrm{NO}_{x}$ emissions without significant losses in the efficiency and reliability of boiler plants running on various types of fuel. Another equally important way to reduce nitrogen oxide emissions is to optimize the combustion process. With a comprehensive reduction in nitrogen oxide emissions, it is important, first of all, to optimize the combustion processes by regime measures. Increasing the concentration of coal dust in the air mixture can accelerate the release and ignition of volatile substances, flame propagation, combustion of coke residue, reduce chemical and mechanical underburning and at the same time suppress the formation of nitrogen oxides [1]. It is very important that the optimal modes can be easily set during the operation of standard installations.

Combustion efficiency is determined mainly by the ratio of air to fuel, as well as the proper distribution of air inside the boiler. Therefore, the choice of the optimal balance between fuel and air is a determining factor in minimizing $\mathrm{NO}_{x}$ emissions and improving the efficiency of the combustion process. In the case of boilers using pulverized coal fuel, especially of low quality, it is very difficult to find and maintain such a balance by traditional methods. Therefore, there is a need to create intelligent systems based on artificial intelligence technologies (neural networks, genetic algorithms, etc.) that allow continuous monitoring of the flame and control the combustion process. This makes it possible to increase the efficiency of the boiler plant, reduce fuel consumption and reduce nitrogen oxide emissions. During optimizing the combustion process due to regime factors, it is possible to reduce NO emissions by $10-40 \%$ (a large figure applies to boilers that burn natural gas or highly reactive coal). In the case of low-reaction and high-slagging fuels, the implantation of low-toxic combustion without appropriate reconstruction of the combustion chamber can cause slagging of the screens, high-temperature corrosion, or an increase in losses with under burning of fuel [2].

The issue of Kazakhstan's place in the system of global economic process is acquiring great importance, which is largely due to the acceleration of its own economic growth. An assessment of the role and significance of the changes taking place in the country, aimed at modernizing and diversifying the domestic economy which is necessary for the subsequent long-term development of Kazakhstan. Thermal power plant (TPP) industry includes continuous production of heat and electricity. A solid fuel (coal) will remain as the main source for energy production at present and shortly. Combustion of organic fuels at TPPs is associated with the emission of harmful fuel combustion products; nitrogen oxides are one of the most toxic components of TPP emissions. Nitrogen oxide (NO) and nitrogen dioxide $\left(\mathrm{NO}_{2}\right)$ play a special role in the content in the atmospheric air and biological effect. Their sum is usually denoted as $\mathrm{NO}_{x}$.

With an increase in the power of power boilers, the yield of nitrogen oxides increases. The maximum yield of nitrogen oxides is observed in the active combustion zone. In other zones, where the temperature level is relatively lower, atmospheric nitrogen is practically not oxidized [3]. Therefore, the reduction of emissions of nitrogen oxides with flue gases of power plants is ensured by the regime and design measures aimed at reducing the formation of gases in boiler furnaces:

- recirculation of flue gases;

- combustion of fuel with extremely low excess air;

- staged fuel combustion;

- injection of moisture into the combustion zone;

- development of new types of burners and various constructive solutions for combustion devices;

- combination of the above methods. 
The choice of the optimal method for reducing the content of nitrogen oxides in the combustion chamber is significantly influenced by the power of the boiler and the type of fuel (gaseous, liquid, solid). At gas-and-oil power boilers, a regime and constructive measures can reduce the emission of nitrogen oxides by $35-40 \%$. At the same time, the increase in the cost of thermal power plants does not exceed $2 \%$. When burning solid fuels, the use of even a set of design and operational measures can reduce the emission of nitrogen oxides by no more than $25 \%$. Flue gas cleaning is a promising way to reduce nitrogen oxide emissions. Nitrogen purification plants should be used only after the exhaustion of the possibilities - suppression of the reaction's formation of nitrogen oxides by relatively cheap technological methods, for the purification of flue gases from nitrogen is a relatively expensive measure. Combustion of fuel with small excess air is based on the known dependence of the reduction in the formation of nitrogen oxides in the initial section of the burner flame with the decrease in temperature. The disadvantage of this method results in simultaneous increase in the degree of burning of the fuel. Combustion of fuel with recirculation of combustion products into the furnace chamber is a common way to reduce the combustion of pulverized coal. The greatest effect on reducing the $\mathrm{NO}_{x}$ output is achieved when recirculation is imposed directly into the hot air front of the burners.

\section{Materials and methods}

For the prediction of $\mathrm{NO}_{x}$ emissions, the ANSYS Fluent [4] software solution solves the transport equation (1). When fuel nitrogen is specified, ANSYS Fluent solves additional transport equations for intermediates such as $\mathrm{HCN}, \mathrm{NH}_{3}$. The $\mathrm{NO}_{x}$ transport equations are solved based on the flow data and the solutions to the combustion equations. The $\mathrm{NO}_{x}$ output results are processed after solving the equations of the burning process. The higher the accuracy of the solutions of the burning process equations, the higher the accuracy of obtaining data on $\mathrm{NO}_{x}$ emissions. The influence of the residence time of the initial components on the mechanisms of formation of nitrogen oxides is taken into account through the variables of the convection process in the constitutive [5-7]. For the mechanism of formation of thermal and fast $\mathrm{NO}_{x}$, only one equation is needed:

$$
\frac{\partial}{\partial T}\left(\rho \cdot Y_{\mathrm{NO}}\right)+\nabla\left(\rho \bar{v} Y_{\mathrm{NO}}\right)=\nabla\left(\rho D Y_{\mathrm{NO}}\right)+S_{\mathrm{NO}}
$$

where $Y_{\mathrm{NO}}-$ a mass fraction $\mathrm{NO} ; S_{\mathrm{NO}}-$ a user-definable constant.

The scheme for calculating the formation of nitrogen oxides according to the model presented in $[8,9]$ is based on simplified gross reactions:

$$
\begin{gathered}
\frac{d C_{\mathrm{N}_{2}}}{d t}=0.5 \cdot 10^{8} \exp \left(-\frac{1000}{T_{g}}\right) \cdot \frac{C_{\mathrm{N}}}{T_{g}}, \\
\frac{d C_{\mathrm{N}_{2}}}{d t}=\left[\frac{1}{2}+\frac{\operatorname{arctg}\left(22.2 \cdot V^{p}-4.7\right)}{\pi}\right] \cdot 1500 \exp \left(\frac{4500}{T^{p}}\right) \cdot\left(C_{\mathrm{NO}}-C_{\mathrm{N}_{2}}\right), \\
\frac{d C_{\mathrm{NO}}}{d t}=0.175 \cdot 10^{14} \exp \left(-\frac{3000}{T_{g}}\right) \cdot C_{\mathrm{N}} \cdot\left(\frac{r_{\mathrm{O}_{2}}}{T_{g}}\right)^{2}=7.75 \cdot\left(-\frac{67790}{T_{g}}\right) \cdot 0.79 \cdot\left(\frac{r_{\mathrm{O}_{2}}}{T_{g}}\right)^{0.5}, \\
C_{\mathrm{N}}=C_{\mathrm{N}_{\tau}}-C_{\mathrm{N}_{2}}-\frac{M_{\mathrm{N}}}{M_{\mathrm{NO}}} \cdot C_{\mathrm{NO}}, \\
C_{\mathrm{NO}}=\frac{1}{L \cdot \alpha} \cdot \psi \cdot N^{p}, \\
\psi_{N}=\frac{1+4861 \cdot 0.01 \cdot V^{p}+3545 \exp \left(\frac{85700}{R T}\right)}{1+3545 \exp \left(\frac{85700}{R T}\right)},
\end{gathered}
$$


here $C_{\mathrm{N}}, C_{\mathrm{N}_{2}}, C_{\mathrm{NO}}$ - mass concentrations of gas-phase nitrogen-containing fuel substances, respectively, in the form of atomic nitrogen; $C_{\mathrm{N}_{2}}, C_{\mathrm{NO}}$ - total mass concentrations of nitrogen-containing substances leaving the fuel, current and final; $r_{\mathrm{O}_{2}}$ - oxygen volume concentration; $R \approx 8.3 \mathrm{~J} /(\mathrm{kmol} . \mathrm{K})$ - gas constant; $V^{r}$ - content (integral yield) of volatiles relative to the mass of the fuel, $\% ; T_{g}, T_{p}$ - temperatures of gas and fuel particles.

To carry out numerical studies to analyze the generation of nitrogen oxides during the combustion of pulverized fuel in boiler furnaces concerning the problem of choosing a model from several options, it is advisable to use reduced kinetic schemes, but ensuring the prediction of the NO concentration in the furnaces chamber with sufficient accuracy. For this, in addition to the kinetic scheme, the model of formation of nitrogen oxides during combustion of pulverized fuel in a torch should provide information on the processes of release and combustion of volatile fuel substances, combustion of coke particles, take into account the aeromechanics of the process [2, 7, 10-12].

Air nitrogen oxides include thermal nitrogen oxides, which are formed especially intensively in the high-temperature combustion zone (at temperatures above $1800 \mathrm{~K}$ ), and fast nitrogen oxides, which are formed at relatively low temperatures in the region of the front of hydrocarbon flames. Thermal nitrogen oxides are formed according to the extended (third reaction) kinetic mechanism described in [8]:

$$
\begin{gathered}
\mathrm{O}+\mathrm{N}_{2} \leftrightarrow \mathrm{NO}+\mathrm{N}, \\
\mathrm{N}+\mathrm{O}_{2} \leftrightarrow \mathrm{NO}+\mathrm{O}, \\
\mathrm{N}+\mathrm{OH} \leftrightarrow \mathrm{NO}+\mathrm{H} .
\end{gathered}
$$

Atomic oxygen is usually produced by thermal dissociation at temperatures above $2000 \mathrm{~K}$ :

$$
\mathrm{O}_{2} \leftrightarrow \mathrm{O}+\mathrm{O}-495 \mathrm{~kJ} / \mathrm{kmol}
$$

It is considered that atomic oxygen is in thermal equilibrium with molecular one.

In the near future, given the current level of $\mathrm{NO}_{x}$ emissions, even with the construction of chimneys with a height of more than $400 \mathrm{~m}$, the sanitary standards for gas pollution in the surface air layer will not be able to be met. Therefore, at present, one of the ways to reduce emissions of toxic products of energy fuel combustion by thermal power plants is a comprehensive study of the formation of nitrogen oxides in the combustion zone using the established regularities of this process to reduce the concentration of nitrogen oxides $\left(\mathrm{NO}_{x}\right)$ in flue gases to a level below $0.5 \mathrm{~g} / \mathrm{m}^{3}$. The problems of protecting the atmosphere from emissions of nitrogen oxides with flue gases of solid fuel thermal power plants, in general, can be solved in the following ways $[3,4,13,14]$ :

- purification of flue gases from nitrogen oxides before being released into the atmosphere;

- preventing the $\mathrm{NO}_{x}$ formation.

Purification of flue gases from nitrogen oxides is associated with certain difficulties, namely: huge volumes of exhaust gases at relatively low concentrations of $\mathrm{NO}_{x}$, low chemical reactivity of nitrogen oxide, as well as the presence of other components in the gases. The use of existing methods for cleaning flue gases requires significant investments, energy costs, etc. [15, 16], which exceed by one or two orders of magnitude the costs of technological methods for suppressing the formation of nitrogen oxides in boiler furnaces.

\section{Results end discussions}

\section{1. Experimental procedures}

According to the experimental data, in the conditions of combustion of a pulverized coal flare, mainly fuel nitrogen oxides are formed.

Fuel nitrogen oxides are formed from nitrogen-containing fuel compounds when blowing hot air already at $T=900 \div 1000 \mathrm{~K}$. At $T=900 \div 1400 \mathrm{~K}$, a significant NO output is detected in the 
initial part of the flare, where the release, ignition and combustion of volatiles occur. The mechanism of formation of fuel oxides of nitrogen is of particular interest, in particular, for Ekibastuz coal $\left(N^{r}=1 \div 1.7 \%\right)$ and also to a certain extent for brown coals, which are burned at low temperatures $T=1600 \div 1700 \mathrm{~K}$ when the share of fuel oxides can be about $75 \%$ of the total volume.

Studies have found that the nitrogen released from the fuel is oxidized by oxygen more easily and faster than the molecular nitrogen of the air. The separation of nitrogen atoms (or nitrogen-containing radicals) from other fuel elements requires 1.5-4 times less energy than the dissociation of a nitrogen molecule from air. The formation of fuel nitrogen oxides occurs at relatively low temperatures, which are common for combustion processes, then thermal nitrogen oxides.

According to the data presented in [17], the degree of transition of nitrogen-containing compounds of these coals to nitrogen oxides is close to a constant value:

$$
\frac{C_{\mathrm{NO}}^{T}}{C_{\mathrm{NO}}^{T_{\max }}}=0.20,
$$

if the entire amount of fuel nitrogen was oxidized to NO, then only due to fuel nitrogen during coal combustion could form up to $2 \div 4 \mathrm{~g} / \mathrm{m}^{3} \mathrm{NO}_{x}$.

It has been established that the yield of fuel nitrogen oxides depends weakly on the temperature (at $T>1200 \mathrm{~K}$ ) and very strongly on the $\mathrm{O}_{2}$ content in the combustion zone, as can be seen from the formula of the above authors:

$$
\frac{C_{\mathrm{NO}}^{T}}{C_{\mathrm{NO}}^{T_{\max }}}=7 \cdot 10^{-5} \cdot C_{\mathrm{O}_{2}}^{2}\left(T_{\max }-1025\right)^{0.33},
$$

where $C_{\mathrm{O}_{2}}$ - average oxygen concentration (v. \%) at the site of formation of nitrogen oxides in the flare, $\left(1 \mathrm{v} . \%=20.45 \mathrm{~g} / \mathrm{m}^{3}\right.$ at partial pressure $\left.1 \mathrm{kPa}\right) ; T_{\max }$ - the maximum temperature of this region.

The equation (11) is applicable in the range $T_{\max }=1200 \div 1800 \mathrm{~K}$. The degree of formation of fuel nitrogen oxides increases with an increase in the excess air coefficient. The type of nitrogen-containing compound and the oxygen content in the fuel do not affect the formation of nitrogen oxides. Among the ways to reduce the formation of fuel nitrogen oxides, the methods of step-bystep fuel combustion are studied in more detail. The tests were carried out for $450 \mathrm{MW}$ unit with an excess air coefficient behind the transition zone of 1.15 and behind the air heater of 1.33 . The consumption of Ekibastuz coal at $L H V=15.56 \mathrm{MJ} / \mathrm{kg}, A^{r}=41 \%, W^{r}=7.0 \%$ was about $83.5 \mathrm{~kg} / \mathrm{s}$. The air consumption (at the inlet of the blast fan) for this fuel and primary air consumption for 7 mills was 0.393 and $0.160 \mathrm{Nm}^{3} / \mathrm{s}$. The content of fuels in the slag and entrainment was 7.5 and $4.3 \%$. The heat loss from the exhaust gases, mechanical underburning of the fuel, to the environment and the physical heat of the slag was $4.09 ; 3.88 ; 0.29 \%$. The gross of energy conversion efficiency of the boiler was 91.74 and $92.03 \%$ before and after the tests, with an increase in electricity consumption for own needs by $0.12 \%$.

According to the results obtained, it was found that in the operating mode of the boiler unit, with an increase in the concentration of coal dust in the air mixture from 0.507 to $0.631 \mathrm{~kg} / \mathrm{kg}$, the average concentration of nitrogen oxides was. The average temperature $\mathrm{NO}_{x}^{a v}=864 \mathrm{mg} / \mathrm{Nm}^{3}$ of the flare at the outlet of the burners was $1618 \mathrm{~K}$. In addition, it was found that the increase in dust concentration does not always contribute to an increase in the ignition temperature of volatile substances and the intensification of combustion, but is extreme. Under the operating conditions of the operating burner, the flow rate of air supplied to the combustion of volatiles with a yield of $24.2 \%$ is noticeably less than the stoichiometric value of $2.7 \mathrm{~kg} / \mathrm{kg}$ (corresponding excess air ratio 0.461 ). For this reason, in our opinion, the average temperature of the air mixture and gases at the beginning of the flare did not increase and, accordingly, the degree of gasification of the fuel increased neither. Therefore, it can be assumed that the thermal mode of operation of the operating burner was not sufficiently optimized in terms of minimizing the formation of nitrogen oxides and combustion processes in general. 


\section{2. Experimental installations, methods and results of the experiment}

The main installation [18] (Fig. 1), additional installations were adapted and set up to study the pyrolysis and gasification of coal dust in the suspended state in the layer (pyrolytic attachment to chromatograph «Color», «LKhM-8MD» «KhPM-4»).

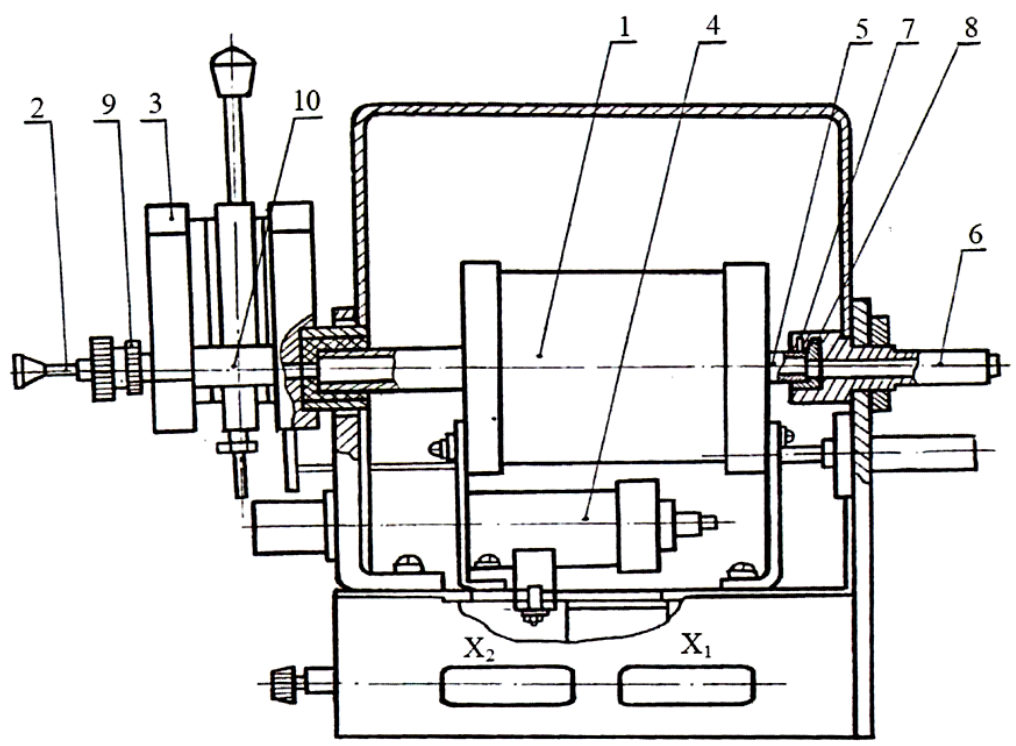

Fig. 1. Experimental set up: 1 - pyrolysis oven; 2 - guide; 3 - crane; 4 - combustion furnace; 5 - tube; 6 - fitting; 7-8-gaskets; 9 - nut; 10 - tap

\section{3. Analysis of the calculation results for $\mathrm{NO}_{x}$}

The analysis of the data obtained consists of a comprehensive consideration of the simulation results, comparing them with experimental data and with the known experimental results of other authors and calculation methods. It can be seen from the analysis that two trends can be traced in the construction of mathematical calculation models. It is preferable to use simplified schemes according to the above equations of total kinetics by making refinements to these schemes.

First of all, based on the available experimental data, it is necessary to clarify the accounting for the release of fuel nitrogen from coal particles. From the four temperature dependence of the degree of gasification of fuel nitrogen for Ekibastuz coal, constructed relying on various literature data (Fig. 2), only curve 1 does not contradict the experimental data [18]. According to these data, the release of a volatile substance from the coal dust of the Ekibastuz coal in a suspended state ends at $1020 \mathrm{~K}$ temperature.

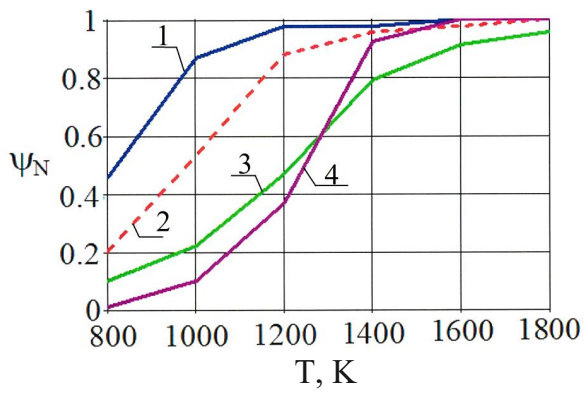

Fig. 2. The degree of fuel nitrogen gasification depending on the temperature for Ekibastuz coal:

1, 2 - T. Vilensky; 3 - D. Pershing, J. Wendt; 4 - V. Babiy

Calculations and processing of the results of experiments carried out at the Department of Thermal Power Engineering [18] are presented with the presentation of individual conclusions in graphical form in this work. It is shown in the presented curves $2-5$ in Fig. 2 that the higher the 
oxygen concentration, the less atomic nitrogen recombines into molecular nitrogen at the same temperature $T$. This can be explained by the fact that with an increase in oxygen concentration, reactive atomic nitrogen reacts with oxygen with an increase in the degree of formation of nitric oxide (see below: curves 3-4 in Fig. 3). From the calculated data presented in Fig. 3, it can be seen that the higher the temperature, the faster the release of atomic nitrogen and its recombination into molecular nitrogen. In this case, the indicated recombination ends at lower values of the oxygen concentration.

Fig. 5 presents the results obtained in [19]. As can be seen from the above calculation results in a very short time and under usual conditions of the burning process $T=1800-1600 \mathrm{~K}$; at oxygen concentration $\mathrm{O}_{2}$ no more than $3 \%$ of flue gases, this recombination ends in less than $0.4 \mathrm{~s}$ (see curves 6 and 5 in Fig. 3) [1]. Consequently, the recombination of atomic nitrogen into molecular nitrogen under usual conditions of a full-scale burning process occurs in the furnace at a distance of no more than one meter from the burner exit, which corresponds to a dimensionless distance from the burner nozzle of about one calibre.

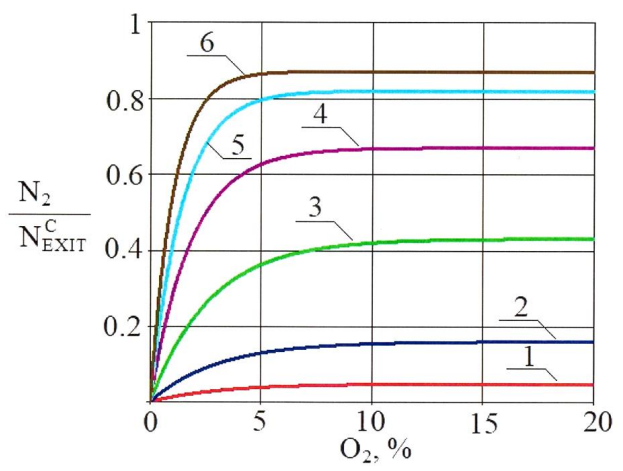

Fig. 3. The recombination of atomic nitrogen at various oxygen concentrations $\mathrm{O}_{2}=1,5,10,15,20 \%$ and temperatures: $T=800,1000,1200,1400,1600,1800 \mathrm{~K}$ (curves 1, 2, 3, 4, 5, 6- respectively)

Fig. 4 shows the results of calculating the formation of fuel nitrogen oxides depending on the temperature change $T=800-1800 \mathrm{~K}$ in the zone of process and oxygen concentration (calculated curves 1, 2, 3, 4 respectively) $[2,11,12]$.

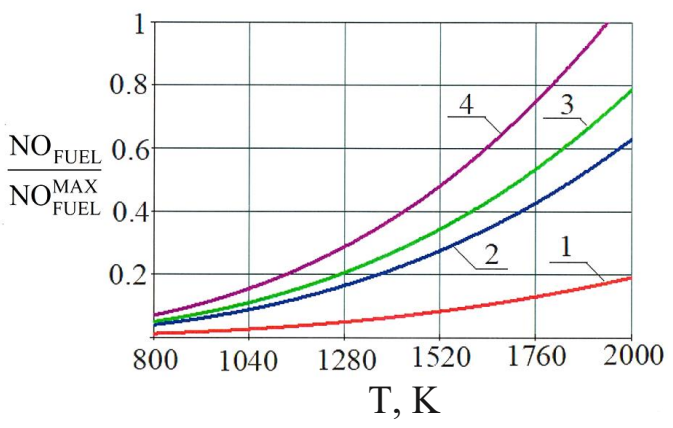

Fig. 4. Formation of nitric oxide $\mathrm{NO}$ fuel at different temperatures $T$ and oxygen concentration $\mathrm{O}_{2}$

In Fig. 5 lines 1, 2, 3 and 4 show oxygen content 1, 3, 7 and $14 \%$ at $N_{\text {fuel }}^{\max }=4 \cdot 10^{-4} \mathrm{~kg} / \mathrm{Nm}^{3}$. From the results shown in Fig. 4, it can be seen that a decrease in the flow temperature leads to a decrease in the formation of and that at low temperatures nitrogen oxides are generated mainly from the nitrogen of the fuel.

It is also notable that a decrease in the oxygen concentration in the carrier flow leads to a sharp decrease in the formation of NO and a decrease in the final yield of nitrogen oxides.

The process of recombination of atomic nitrogen into molecular nitrogen at various values of the oxygen concentration $\mathrm{O}_{2}$ (Fig. 5) and temperature $T$ corresponding in its level to the 
temperatures of the real burning process in the boiler furnace (Fig. 3, curves 1, 2, 3, 4, 5, 6) in the region of the recombination reaction occurs in a very short time (less than $0.4 \mathrm{~s}$ ). Hence, it can be concluded that the region of recombination in the combustion zone of the pulverized coal flame in the boiler is at a distance from the nozzle exit of the burner no more than one meter.

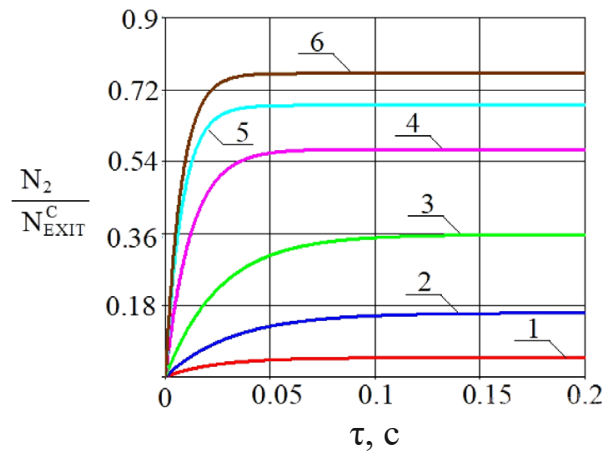

Fig. 5. The recombination of atomic nitrogen $\mathrm{N}$ in $\mathrm{N}_{2}$ at different concentration values $\mathrm{O}_{2}$ : $\mathrm{O}_{2}=1,3,7,14 \%$ respectively and temperature $T(T=800,1000,1200,1400,1600,1800 \mathrm{~K})$ curves $1,2,3,4,5,6$ - respectively, depending on the time of the recombination process [17]

As from the above-calculated data (Fig. 2-5) it follows that the main formation of nitrogen oxides occurs in the area of the release of volatiles from coal particles. At low temperatures (less than $900 \mathrm{~K}$ ), volatiles does not ignite, and fuel nitrogen oxides are almost not formed [19]. In this case, of particular interest is the temperature range above $900 \mathrm{~K}$, where the formation of nitrogen oxides begins and up to the temperature range where the formation of nitrogen oxides reaches the limiting value. The computer programs and calculations of the processes of formation of oxides of nitrogen of high-concentration Ekibastuz coal combustion were developed.

Table 1 is presented calculations data of the kinetics of formation of nitrogen oxides.

Table 1

Tabular data of calculations of the kinetics of formation of nitrogen oxides

\begin{tabular}{cccc}
\hline Temperature, $\mathbf{K}$ & Concentration, $\%$ & Volume, $\mathbf{~ k g} / \mathbf{n m}^{\mathbf{3}}$ & Enthalpy, $\mathbf{~ J J} / \mathbf{k g}$ \\
\hline 800 & 0.000907 & 0.000033596 & 5870.2 \\
1000 & 0.179790 & 0.000066444 & 7524.0 \\
1200 & 0.447250 & 0.000165290 & 9198.8 \\
1400 & 0.717730 & 0.000265250 & 10995.1 \\
1600 & 0.861990 & 0.000318560 & 12766.2 \\
1800 & 0.926692 & 0.000342550 & 14570.8 \\
2000 & 0.975684 & 0.000387220 & 16408.9
\end{tabular}

A fire-technical method for suppressing the formation of nitrogen oxides by pyrolysis of fuel with air retention is proposed, which allows reducing the emissions of nitrogen oxides to the level of modern requirements [20]. The environmental and economic advantages of the proposed method in comparison with the existing ones in the field of both modernized and newly designed furnace devices are noted. The objectives of further research are to study the real possibilities of reducing nitrogen oxide with carbon and to develop engineering methods for implementing the results of research on the topic.

\section{4. Influence of coal dust temperature on velocity profiles in the gasification zone}

During flare combustion in boiler furnaces in the heating zone of coal particles during the release of volatile substances, part of the nitrogen-containing compounds is initially released in the form of vapours and gases. The latter is oxidized to form nitrogen oxides. Fuel nitrogen remaining 
in the coke is also partially converted into nitrogen oxide during afterburning, but it is insignificant in comparison with the emission of fuel nitrogen oxides from the gas phase. Experimental data [1] show that the formation of fuel nitrogen oxides in the flare ends at the site of volatiles burnout. Further, in the area of coke residue burnout, their concentration practically does not increase. Therefore, the question of the regularities of fuel nitrogen gasification becomes very important. In this work [1], significantly different nature of the dependence of the yield of volatiles and gasification of fuel nitrogen on the pyrolysis temperature $\psi_{\mathrm{N}}=10 \div 15,40 \%$ at $T=600$ and $1000 \div 1200 \mathrm{~K}$ for bituminous coals of the Kentucky, Pittsburgh and Lignite deposits; $2 \div 18 \%$ at $900 \div 1800 \mathrm{~K}$ bituminous coals of the Pittsburgh deposits, and $\psi_{\mathrm{N}}=0 \div 0.9$, exponentially at $T=600 \div 2200 \mathrm{~K}$ and $0 \div 0.85$ at $1200 \div 1800 \mathrm{~K}$ for the specified coals is noted. At higher temperatures, the concentration of nitrogen-containing components in volatiles is higher than at low temperatures.

Fig. 6 shows that the tangential component of the velocity created by argon tends to decrease, which is highlighted in the figure by the red outline.

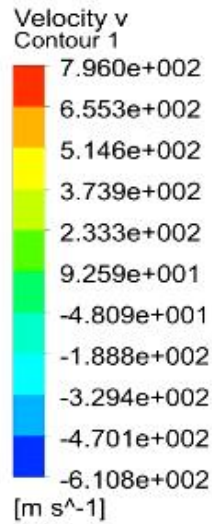

Velocity $\mathrm{V}$
Contour 1

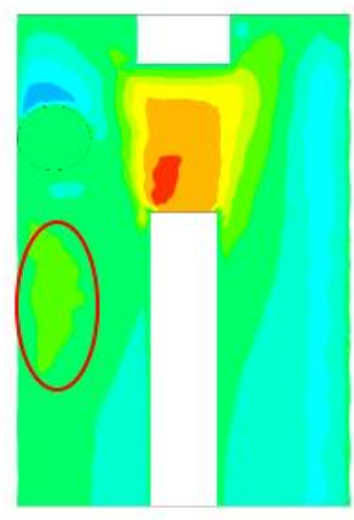

$500 \mathrm{~K}$

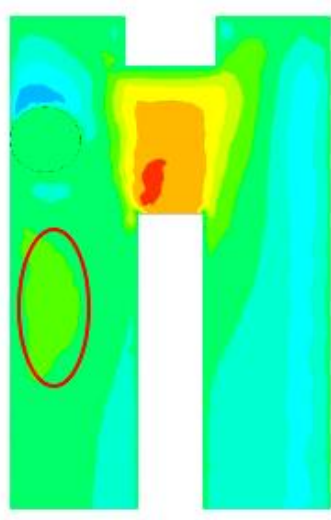

$600 \mathrm{~K}$

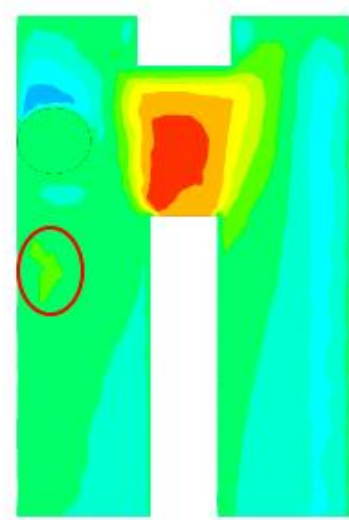

$700 \mathrm{~K}$

Fig. 6. Axial velocity profiles at different temperatures of coal dust [17]

\section{5. Influence of coal dust temperature on gas temperature profiles in the gasifica- tion zone \\ Fig. 7 shows that with an increase in the temperature of coal dust, the high-temperature zone shifts to the outlet of the model. The latter can be explained by high-speed streams. Air, which has less resistance, pushes high-temperature gases towards the yield area.}

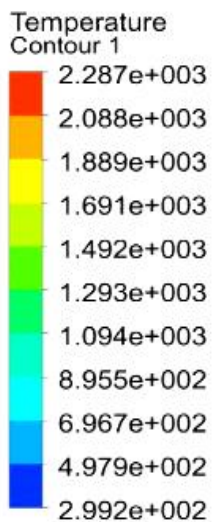

[K]
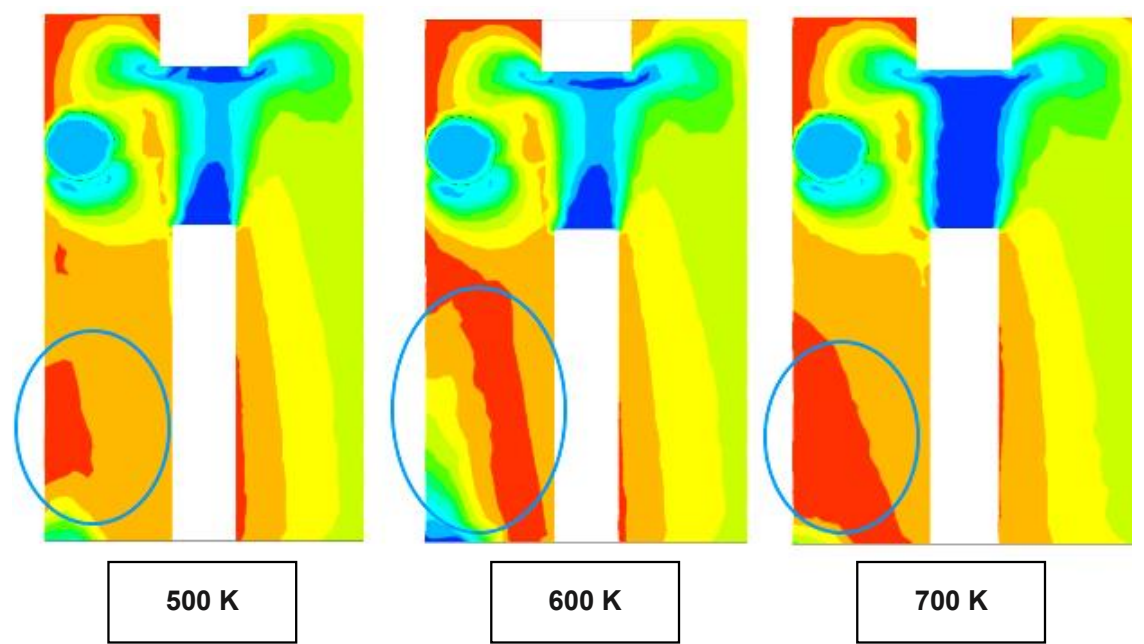

Fig. 7. Temperature profiles versus coal dust temperature [17] 
This work is aimed at finding ways to further reduce emissions of toxic products from the combustion of pulverized coal fuel by means of preliminary gasification of fuel at the initial section of the pulverized coal flame of a vortex burner with a delay in the supply of air to the air mixture until it enters the ignition zone in the furnace volume of the boiler unit.

\section{Conclusions}

The installation and debugging of firing installations for studying the pyrolysis of coal dust and combustion of pyrolysis products with a phase shift of the air supply have been developed and carried out.

Experiments were carried out to study the formation of nitrogen oxides in an inert and air environment using a pyrolytic attachment and experimental methods using chromatographs LKhM-8MD, KhPM-4 and the Evdiometer-1 device.

It is shown that despite the presence of oxygen in the Ekibastuz coal in the amount of exhaust gas, $O^{d a f}=11.8 \%$ in an inert atmosphere, nitrogen oxides are not formed. The content of nitrogen oxide NO in the air was $340 \div 670 \mathrm{mg} / \mathrm{m}^{3}$ with a change in the process temperature from 770 to $1170 \mathrm{~K}$.

The possibility of suppressing the formation of nitrogen oxides up to three or more times by pyrolysis of dust from Ekibastuz coal at temperatures $770 \div 970 \mathrm{~K}$ and a phase shift in the supply of air for combustion to $0.1 \mathrm{~s}$.

It is shown that in the temperature range above $900 \mathrm{~K}$ the formation of nitrogen oxides begins and at temperatures above $1600 \mathrm{~K}$ the formation of nitrogen oxides reaches its limiting value.

Mathematical processing of the results and the developed mathematical model of this area are in good line with the experimental results.

\section{References}

[1] Belikov, S. E. (2006). Integrated development of methods for reducing emissions of nitrogen oxides from thermal power plants by optimization of the combustion process and methods of fuel combustion. Moscow, 282.

[2] Ongar, B., Iliev, I., Smagulova, G., Mergalimova, A. (2020). Numerical Simulation of the Formation of Nitrogen Oxides in Pulverized Furnaces. Journal of Engineering Science and Technology Review, 171-175. Available at: http://www.jestr.org/ downloads/SpecialIssue2020/fulltext36SE.pdf

[3] Umyshev, D. R., Dostiyarov, A. M., Tyutebayeva, G. M. (2017). Experimental investigation of the management of $\mathrm{NO}_{x}$ emissions and their dependence on different types of fuel supply. Espacios, 38 (24).

[4] Umyshev, D., Iliev, I. (2020). Research of the Combustion Process in a Heat Generator with Ansys Fluent. 2020 7th International Conference on Energy Efficiency and Agricultural Engineering(EE\&AE). doi: https://doi.org/10.1109/eeae49144.2020.9279022

[5] Al-Abbas, A. H., Naser, J., Dodds, D. (2011). CFD modelling of air-fired and oxy-fuel combustion of lignite in a 100KW furnace. Fuel, 90 (5), 1778-1795. doi: https://doi.org/10.1016/j.fuel.2011.01.014

[6] Yang, J., Golovitchev, V. I., Redón Lurbe, P., López Sánchez, J. J. (2012). Chemical Kinetic Study of Nitrogen Oxides Formation Trends in Biodiesel Combustion. International Journal of Chemical Engineering, 2012, 1-22. doi: https://doi.org/ $10.1155 / 2012 / 898742$

[7] Chernetsky, M., Dekterev, A. (2011). Mathematical model of the processes of heat exchange and burning of pulverized coal in flaring. The physics of combustion and explosion, 3, 37-46.

[8] Abildinova, S. K., Musabekov, R. A., Rasmukhametova, A. S., Ongar, B., Yessengabylov, I. Zh., Aldabergenova, A. O., Issayeva, G. B. (2018). The efficiency of district heating systems in conditions of joint use of heat pumps. News of the National Academy of Sciences of the Republic of Kazakhstan. Series of Geology and Technical Sciences, 4 (430), $201-207$.

[9] Mergalimova, A., Ongar, B., Georgiev, A., Kalieva, K., Abitaeva, R., Bissenbayev, P. (2021). Parameters of heat treatment of coal to obtain combustible volatile substances. Energy, 224, 120088. doi: https://doi.org/10.1016/j.energy.2021.120088

[10] Zhitarenko, V., Bejan, V., Ostapenko, O. (2020). Adaptation of mathematical model of heat and energy characteristics of medium pressure boilers to real operating conditions. Technology Audit and Production Reserves, 4 (1 (54)), 23-30. doi: https://doi.org/10.15587/2706-5448.2020.210540

[11] Enyakin, Yu. P., Usman, Yu. M., Vereshetin, V. A. (2001). Development and research of burners with a reduced yield of nitrogen oxides. Bulletin of the Academy of Industrial Ecology, 1, 53-62.

[12] Habib, M. A., Elshafei, M., Dajani, M. (2008). Influence of combustion parameters on NOx production in an industrial boiler. Computers \& Fluids, 37 (1), 12-23. doi: https://doi.org/10.1016/j.compfluid.2007.04.006 
[13] Shi, L., Fu, Z., Duan, X., Cheng, C., Shen, Y., Liu, B., Wang, R. (2016). Influence of combustion system retrofit on $\mathrm{NO}_{x}$ formation characteristics in a $300 \mathrm{MW}$ tangentially fired furnace. Applied Thermal Engineering, 98, 766-777. doi: https:/doi.org/ 10.1016/j.applthermaleng.2015.12.026

[14] Cardona Vargas, A., Arrieta, C. E., Tumay, H. A. Y., Echeverri-Uribe, C., Amell, A. (2021). Determination of laminar burning velocity of methane/air flames in sub atmospheric environments. EUREKA: Physics and Engineering, 4, 50-62. doi: https://doi.org/10.21303/2461-4262.2021.001775

[15] Vascellari, M., Cau, G. (2012). Influence of turbulence-chemical interaction on CFD pulverized coal MILD combustion modeling. Fuel, 101, 90-101. doi: https://doi.org/10.1016/j.fuel.2011.07.042

[16] Komissarov, K. B., Lutkov, S. A., Fil, A. V. (2007). Complex purification of flue gases of heat-generating plants. Rostovon-Don: Branch of FSEIHPE, 134.

[17] Ongar, B. (2018). The numerical research of the laws of the formation of nitrogen oxides during combustion of partially gasified coal. 6D071700 - Heat power engineering. Almaty: AUPET, 112.

[18] Titov, S. P., Babiy, V. I., Barbarash, V. M. (1980). Study of NOx formation during combustion of coal dust. Heat power engineering, 3, 64-67.

[19] Temirbaev, D. Zh. et. al. (2015). Pat. No. 90006 RK. Vortex pulverized coal burner. No. 30470/F23D1/02; published: 15.10.2015, Bul. No. 10.

[20] Reid, D., Cabe, J. E., Bearden, M. D. (2010). PNNL Coal Gasification Research. Pacific Northwest National Laboratory Richland. Washington. doi: https://doi.org/10.2172/985585

Received date 20.09.2021

Accepted date 20.11.2021

Published date 10.01.2022
(C) The Author(s) 2021

This is an open access article under the Creative Commons CC BY license

How to cite: Ongar, B., Beloev, H., Iliev, I., Ibrasheva, A., Yegzekova, A. (2022). Numerical simulation of nitrogen oxide formation in dust furnaces. EUREKA: Physics and Engineering, 1, 23-33. doi: https://doi.org/10.21303/2461-4262.2022.002102 